\title{
Effect of the Orientation on the Comfort of a Building Made with Compressed Earth Block
}

\author{
Fati Amadou Oumarou ${ }^{1,2 *}$, Adama Ouedraogo ${ }^{1,3}$, Sikoudouin Maurice Thierry Ky ${ }^{1}$, \\ Ramchandra Bhandari", Amadou Konfe', Ramatou Konate', Rabani Adamou², \\ Dieudonné Joseph Bathiebo' ${ }^{1}$, Sié Kam ${ }^{1}$
}

${ }^{1}$ Laboratory of Renewable Thermal Energies, University Joseph KI-ZERBO: UFR/SEA, Ouagadougou, Burkina Faso ${ }^{2}$ Faculty of Science and Technologies, Department of Chemistry, University Abdou Moumouni, Niamey, Niger ${ }^{3}$ Centre Universitaire Polytechnique de Kaya (CUP-Kaya), University Joseph KI-ZERBO, Ouagadougou, Burkina Faso ${ }^{4}$ Institute for Technology and Resources Management in the Tropics and Subtropics: ITT, Cologne, Germany

Email: ^amadoufatiouma@gmaill.com

How to cite this paper: Oumarou, F.A., Ouedraogo, A., Ky, S.M.T., Bhandari, R., Konfe, A., Konate, R., Adamou, R., Bathiebo, D.J. and Kam, S. (2021) Effect of the Orientation on the Comfort of a Building Made with Compressed Earth Block. Smart Grid and Renewable Energy, 12, 99-112. https://doi.org/10.4236/sgre.2021.127007

Received: June 22, 2021

Accepted: July 27, 2021

Published: July 30, 2021

Copyright $\odot 2021$ by author(s) and Scientific Research Publishing Inc. This work is licensed under the Creative Commons Attribution International License (CC BY 4.0).

http://creativecommons.org/licenses/by/4.0/ (c) (i) Open Access

\begin{abstract}
Thermal comfort is one of the most important requirements that scientists and building designers must meet to ensure the indoor air quality knowing its importance on productivity and the health of occupants. However, it has never been of great concern for architects and architectural historians and seldom explores it. Buildings are the large consumer of the most energy consumption (around 40\% worldwide) and generate around 35\% of GHGs like $\mathrm{CO}_{2}$ that leads to extreme climate change. Hence, general and specific eco-friendly solutions in the field of building construction are required. Analysis of this study shows that air conditioning consumption can be significantly reduced thanks to the compressed earth bricks and by taking into account the climate and the orientation of the facades. However, this paper establishes viable low-cost option of building energy consumption while maintaining the thermal comfort and good indoor air quality. This work explains the effect of a single residential room orientation, by reducing the thermal amplitude, and improving the thermal phase shift in Ouagadougou climate conditions in April. Internal temperature was modelled with 8 cardinal orientations. The result corresponds to a decrease of thermal amplitude damping greater than $4^{\circ} \mathrm{C}$ between East-West and North-South sides and, with a thermal phase shift of 4 hours 30 minutes between the Nord and West walls.
\end{abstract}

\section{Keywords}

Thermal Comfort, Building Optimal Orientation, Thermal Amplitude, Thermal Phase Shift, Energy Consumption, Optimal Orientation 


\section{Introduction}

It is a real fact, and studies have shown that man spends almost all of his time, almost $90 \%$ on average according to the air quality observatory [1] [2] [3] [4], in enclosed spaces such as buildings (amphitheaters, supermarkets, gymnasiums and swimming pools). These spaces play an essential role in the economy and society in general, but do not necessarily ensure thermal comfort and good indoor air quality [5] [6]. Many countries worldwide suffer from severe shortage of energy resources and inability to save it. It is necessary to develop an integrated strategy, to make buildings more energy efficient and integrate active and passive design techniques [7]. Since the building orientation is one of the most important factors affecting the energy consumption. Currently, the energy and environmental concerns are marked by two phenomena, the consequences of which give rise to real questions of sustainability: this is partly due first to the increase in pollution and, second, to the sharp decline in exhaustible energy resources (fossil fuels) [8] [9]. Since, during the last two decades because of the issues of environment and ecology, energy conservation and sustainable development have become an essential part of the building industry [10] [11]. Saving this energy consumption, especially in buildings, directly it affects the world's national economy [12] [13].

The building sector is becoming an increasing trend for the future of construction during the coming years [8], enabling environmental sustainability, energy security and also reliability [14]. Indeed, building environment plays vital role for inhabitants' productivity, moral, and satisfaction [15]. Many efforts have been made in this sense to reduce the share of $\mathrm{CO}_{2}$ emissions by buildings trough energy savings and efficient techniques [8] [9] [16]. In Burkina Faso, the building sector, the use of air-conditioners during the long hottest period and huge number of residential units to meet the demands for housing are causing a high peak cooling load and peak electricity consumption, and [1]. The shortage in the traditional energy sources and the early stages in using the renewable energy sources motivated the design of energy saving buildings [12]. Hence, researchers and scientists are working on the energy modeling and control in order to develop strategies that will have impact on the reduction of the energy consumption in building [17]. The objective of the present study is to investigate and determine the impact of the orientation changing in the energy performance of the building. Parameters such orientation variations related to sun radiations and wind direction were investigated and assessed using EcotectTM software to measure energy consumption for air conditioning between West and East orientations by Berghout et al. [18] [19], and their findings showed that consumption was higher for West orientation than East orientation. This was related to the rate of solar radiations absorbed with the higher temperatures obtained with the West orientation. As for the East and West orientations, the deficit stands at 45\%, which is of the same order of magnitude as the results of Givoni (1978) [18].

To show if there is any relationship between orientation and energy consump- 
tion, a case study was undertaken in Constantine new town extension called "Ali Mendjeli new town", where readings of air, surface temperatures and relative humidity were compared to thermal comfort limits for such climatic conditions [20] [21]. Results from this investigation [21] indicated that orientation criterion was a factor to be considered when conceptualizing a more economically powerful design for thermal and energy saving building. Thus, the best orientation was found to be South orientation and an optimal orientation was obtained from $30^{\circ}$ east azimuth to $15^{\circ}$ west azimuth orientation, and which were justified for this type of semi-arid climate. Another investigation's result in the same city of Constantine by Guermia and Fatiha found that, full East and full West orientations should be avoided when designing a building [22]. The dynamic factors of temperature variations (hourly) under the effect of different orientations (north, northeast, east, southeast, south, southwest, west and northwest), have been investigated in Malaysia based on a series of computer simulations using commercially available software [9] by Mohamed Ali et al. [23]. These authors reported first, that the effect of orientation was one of the most important design variables upon the indoor temperature with a value of partial correlation equal to $58 \%$, and second, the orientation of the exposed walls of the terrace house should be on the North-South axis, i.e., facing North and South in order to minimize solar heat gain. From their findings, they stipulated "as a general rule" that the best orientations for all spaces, should be "Southward and Northward", and "Westward and Eastward" being the worst; although, both of which have recorded maximum internal mean temperatures throughout the year compared to other orientations with a peak value of $33.4^{\circ} \mathrm{C}$. All these studies showed that, there is also a relationship between the amount of energy absorbed by the wall and the interior temperature, which was closely dependent on orientation. These authors came to the conclusion that an appropriate orientation is favorable to the control of thermal comfort and to the reduction of energy demand by energy saving while using. In our days, there is no study in the literature based on the orientation in our area that is the motivation of this study.

\section{Studied Area}

Burkina Faso is a Sahelian landlocked country with an area of $274,200 \mathrm{~km}^{2}$ located in the heart of West Africa. According to the Koppen-Geiger classification of climates, Burkina Faso is characterized by a hot and dry tropical climate, with two main seasons: a dry season from mid-October to mid-March and a wet season from mid-March to mid-October [24]. Ouagadougou, the capital of the country is located at Latitude: $12^{\circ} 21.9396^{\prime}$ North and Longitude: $1^{\circ} 32.0328$ West. The rainy season is short and runs from mid-June to early October. The average annual rainfall is around $788 \mathrm{~mm}$ of which $80 \%$ between May and October.

Three distinct climatic seasons can be identified in Ouagadougou: the hot season characterized by high temperatures from March to May, the rainy season from June to October characterized by high relative humidity, and a relatively colder season from November to February dominated by the harmattan of the 
northeast winds. Figure 1 described the three climatic zones of Burkina Faso. There is, the Sudanese zone in the south part, the Sudano-Sahelian zone running from east to west and the Sahelian zone in the north. The Sudano-Sahelian zone is much larger than the other two other. In the hottest months between March and May, the weather is mainly tropical in Burkina Faso, i.e., hot and dry with occasional showers or thunderstorms and creating a huge demand for air-conditioning for comfort cooling [25]. When we look at the temperature's distribution in Ouagadougou, the most frequent is between $24^{\circ} \mathrm{C}$ and $38^{\circ} \mathrm{C}$. The hottest months are distinguished by the proportions of temperatures above $38^{\circ} \mathrm{C}$. These temperatures reach their highest levels in March, April and October, and their lowest in December, January and February. The highest and lowest levels are found in the northern part of the country giving high diurnal, monthly and annual thermal amplitudes. Studies done by Kaboré B et al. [26] showed that the hottest month in Ouagadougou is April. Regardless of the nature of the material used and also how they affect the internal average temperature.

\section{Methodology of Resolution}

This study is based on the geographical position of Ouagadougou. The building energy analysis was performed by using both the COMSOL Multiphysics and MATLAB R2018a software. To do the modeling, we first designed a program to determine the global solar radiation flux that arrives on external walls sides of the building on the typical day of 15th April (the hottest month of the year) in

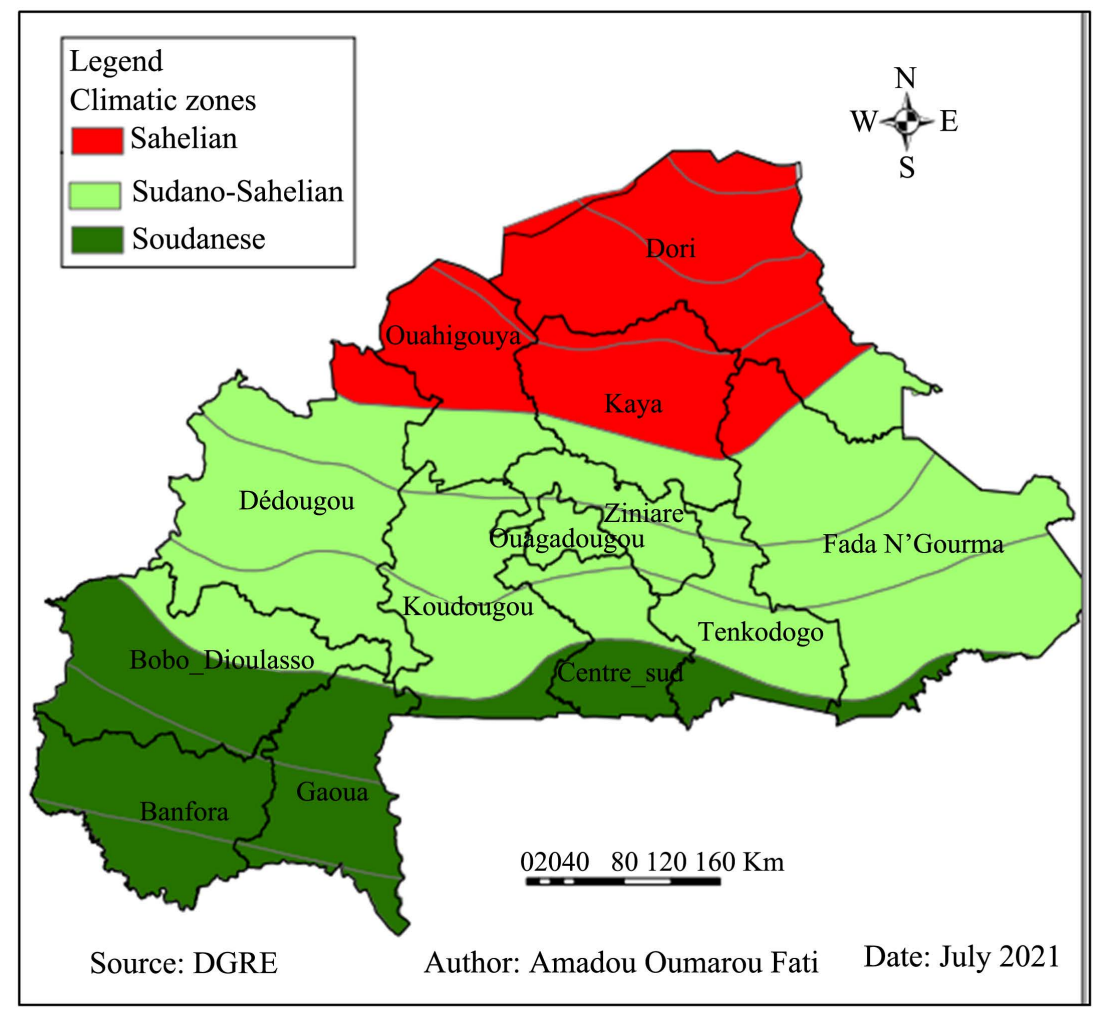

Figure 1. The climatic zones of Burkina Faso. 
Burkina Faso. The result of this program can permit the determination of incidence solar energy that comes from the external faces of a building. Then we are incorporate in the Comsol software. (Figure 2) [27]. To solve the equations of the studied problem, we select the method of finite elements in Comsol software, in order to evaluate the heat transfer. We use the Fourier series equation (1) to simulate the solar fluxes $\left(\mathrm{W} / \mathrm{m}^{2}\right)$, on the different walls of the building envelope. General form of these curves, is shown below:

$$
P_{i}(t)=a_{0, i}+\sum_{n=1}^{4} a_{n, i} \cos \left(n w_{i} t\right)+b_{n, i} \cos \left(n w_{i} t\right)
$$

The main program ability of Transient heat transfer is based on numerical solving of second order Partial Differential Equation (PDE) by finite element method (FEM). The usage of this program for similar problems, namely transient heat transfer can be found in [28]. As input to the software, we introduced the geometric description of a typical monozone single room and the thermo-physical properties of the bricks. The geometry selected for simulation analysis is rectangular $\left(15^{*} 6.66\right) \mathrm{m}^{2}$ habitat built in BTC and the bricks are with a thickness of $20 \mathrm{~cm}$ [15] and $H=4 \mathrm{~m}$.

The thermophysical properties of the material BTC are cited in Table 1 below.

Figure 3 is the chosen building and also the meshing of the case of study. The building model has been meshed with an ultrasoft meshing (1553 point of meshing, 6490 tetrahedrons and 3236 triangles) because of the complexity of the parameters that it integrates and also the small openings involved. This model has served for the study.

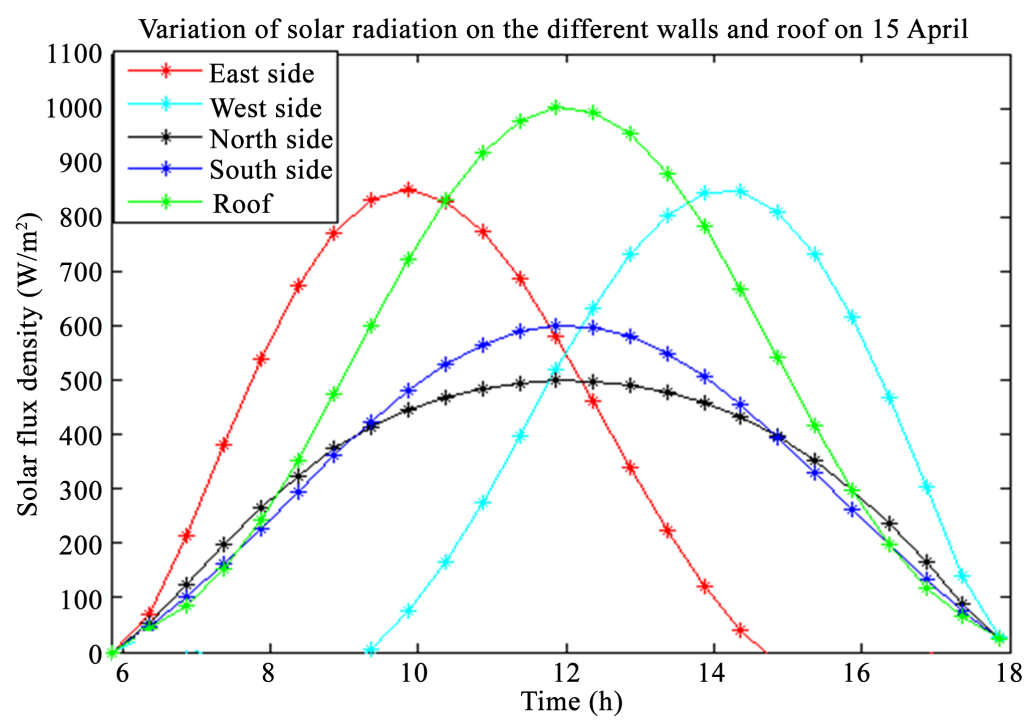

Figure 2. Evolution of global solar heat on each sides of the walls [3].

Table 1. The thermophysical properties of the material BTC [29] [30].

\begin{tabular}{cccc}
\hline & Conductivity $\lambda(\mathrm{W} / \mathrm{m} \cdot \mathrm{K})$ & Density $\rho\left(\mathrm{Kg} / \mathrm{m}^{3}\right)$ & Specific heat $C_{p}(\mathrm{~J} / \mathrm{Kg} \cdot \mathrm{K})$ \\
\hline BTC & 0.671 & 1960 & 1490 \\
\hline
\end{tabular}



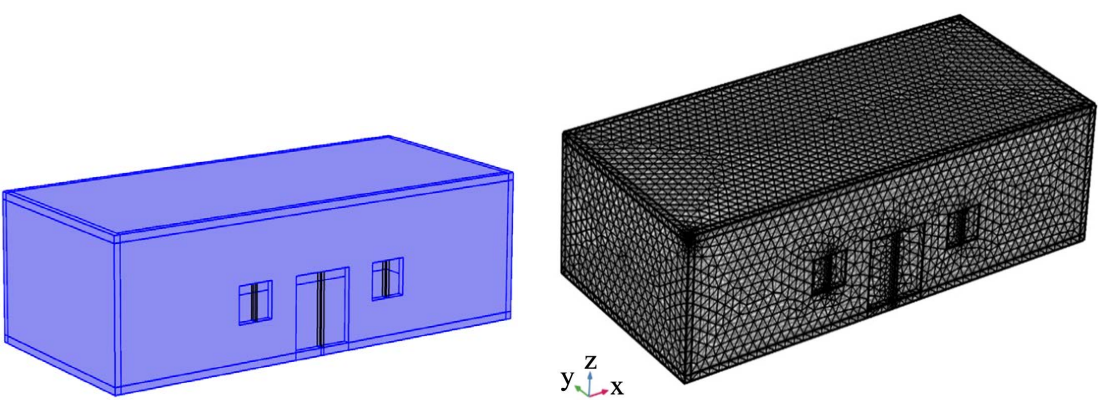

Figure 3. The model of the chosen building.

\section{Heat transfer equations}

The main heat transfer equation in the building is:

$$
\rho \cdot C_{P} \frac{\partial T}{\partial t}+\rho C_{P} U \cdot \nabla T+\nabla \cdot q=Q
$$

where,

$$
q=-\nabla(\lambda T)[28][31]
$$

$T$ is the room temperature, $\rho$ density, $C_{P}$ heat capacity on walls and roof, $U$ velocities, $t$ time, $Q$ heat source. We obtain for each of the walls, the roof and the ground an equation of the type below:

$$
\rho \cdot C_{P} \frac{\partial T}{\partial t}+\nabla \cdot q=Q \quad[15][28]
$$

The thermal balance at all times of the volume of an internal air in a space is taking into account all the flows transmitted by convection and by radiation, assuming that this volume is isothermal.

$$
m_{\text {air }} \rho_{\text {air }} C_{P} \frac{\mathrm{d} T}{\mathrm{~d} t}+\int_{S}(n \cdot q) \mathrm{d} S=Q_{v} \quad \text { [28] [31] }
$$

$\frac{\mathrm{d} T}{\mathrm{~d} t}$ total derivative (temperature); $Q_{\dot{v}}$ : volume heat sources; $m_{\text {air }}=$ masse of

Generally, at this period, in the Sahelian zone, the absolute humidity varies very little during a day. On the other hand, the relative humidity varies a lot like the dry temperature. We then use Bertrand's formula for the calculation of saturated vapor pressures and the classical relationship between relative humidity and absolute humidity. We use Bertrand's Formula:

$$
P_{v s}(T)=10^{\left(17.443-2795 / T(\mathrm{~K})-3.868 * \log _{10}(T(\mathrm{~K}))\right)}
$$

$T(\mathrm{~K}): T$ in Kelvin, $P_{v s}: P(\mathrm{~mm} \mathrm{Hg})$

Relative humidity function of $T$ and absolute humidity, $H_{a b s}$

$$
R H=\frac{P \cdot H_{a b}}{P_{v s} \cdot\left(H_{a b}+0.622\right)}
$$

We consider a well-mixed fluid domain so that temperature of internal air is calculated with (5). The building was modeled and its orientation changed by 45 degrees to calculate the energy received every 45 -degree including the basic 
orientations (North - South - East - West). In order to access the influence of the orientation on the thermal behavior of the building, a comparison of the interior comfort was made for different orientations of the same building.

\section{Boundaries Conditions, Initial Conditions and Hypothesis}

The external conditions were taken into account by means of average temperature and the global radiation flux coming from the sun on each of its facades and the evolution of ambient temperature Each wall exchanges, through its external and internal faces, heat by convection and by radiation, according to the equations below [15] [28] [31]:

Outside:

$$
\begin{gathered}
q_{c v, o}=h_{o}\left(T_{p, o}-T_{a m b}\right) \\
q_{r, o}=\varepsilon \sigma\left(T_{P, o}^{4}-T_{a m b}^{4}\right)
\end{gathered}
$$

Interior

$$
\begin{aligned}
& q_{c v, i}=h_{i}\left(T_{p, i}-T_{i n t}\right) \\
& q_{r}=\varepsilon \sigma\left(T_{P}^{4}-T_{i n t}^{4}\right)
\end{aligned}
$$

In fact, few hypotheses that were considered:

$\checkmark$ Conduction heat transfer is unidirectional;

$\checkmark$ The air is perfectly transparent to radiation and has a uniform temperature;

$\checkmark$ The wind effect is neglected; there are no domestic appliances;

$\checkmark$ The building and the materials are assimilated to a gray body and small opening that can just allow air renewal.

\section{Result and Discussions}

The orientation and the solar radiation on the building are significant factors in the design of the building. In hot regions, such as Burkina Faso which receives sunlight all year round, buildings must be well oriented so as to minimize solar gain, and maximize natural ventilation [15]

Figure 4 below shows the global irradiation coming on the exterior walls during the hot and dry period, in this case that of the month of April, which is considered to be the hottest month in Burkina Faso. Our study is based on the day of April $15^{\text {th }}$. As indicated previously in Figure 2, the roof receives the greatest solar flux. Results in Figure 4 depicted shows that, the radiation of the South-East, East and North faces is present from the sunrise 6 a.m. until around 3 p.m. All these orientations reach their maximum from 8:30 a.m. and 9 a.m. with a value of $900 \mathrm{~W} / \mathrm{m}^{2}$. The maximum fluxes received on the walls are observed at the level of the West and North-West and South-West facades are obtained respectively around $15 \mathrm{~h}$ and 4:30 p.m., and flux is $900 \mathrm{~W} / \mathrm{m}^{2}$ The North and South orientations radiate from sunrise until sunset at 6 p.m. but receive less solar flux. We consider that, the energy is absent early in the morning before 5 p.m. since there is no solar radiation before sun rises. From the hour of sunrise, 


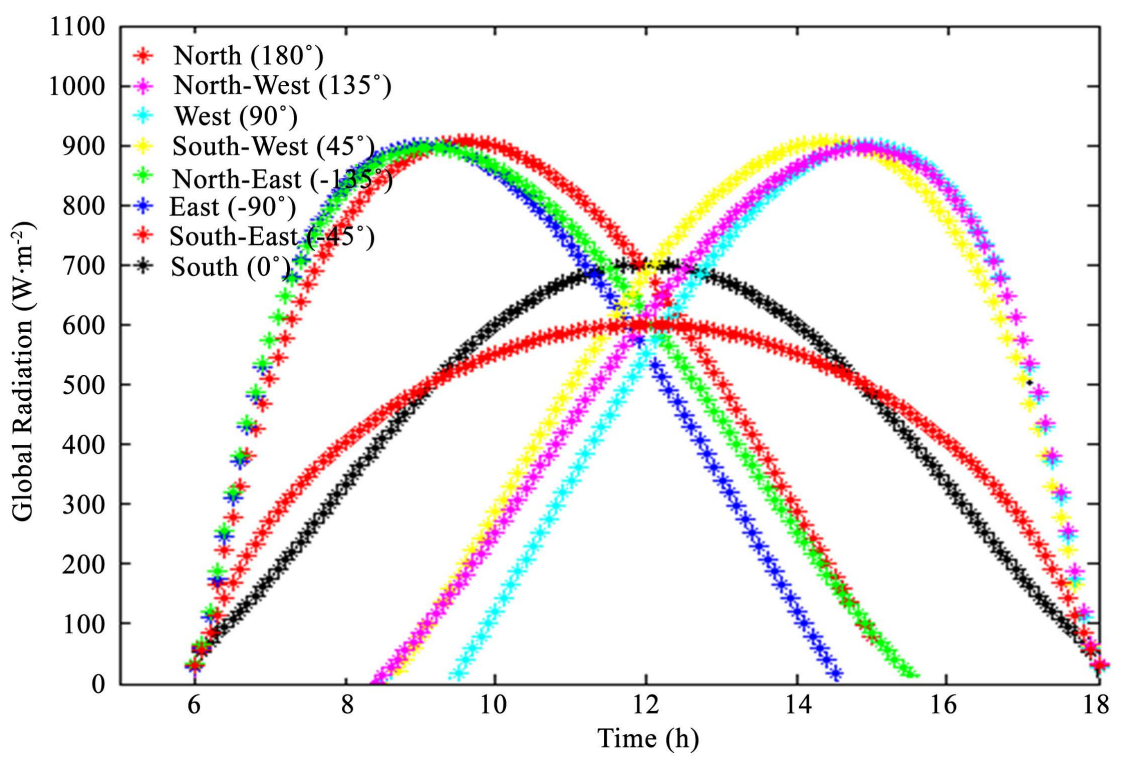

Figure 4. Impact of the orientation on the thermal comfort.

the west, North-west and the south-west faces have an energy which is near to zero. This is why we recommended the architect to orient their building in North instead of the other faces.

\subsection{Cumulative Energy Cumulative Energy over an Area of One Square Meter}

By looking at the cumulative energy in Figure 5, we can say that: in the morning, before noon $(12 \mathrm{~h})$, the northwest, north, south, southwest facades received less solar radiation resulting in a cumulative energy of around $2 \mathrm{kWh}$, compared to the southeast, northeast, and east faces having a maximum energy ranging from $3 \mathrm{kWh}$ to $5 \mathrm{kWh}$. In the Afternoon, the energy received in term of solar radiation by the North, South, North-West, South-West, North-East, East and West facades were in the order of magnitude ranging from $3.5 \mathrm{kWh}$ to $7.5 \mathrm{kWh}$. For the South and North facade there is hardly any energy since it is not exposed to the sun. East and West orientations which received roughly the same amount of sunlight should be avoided. Irradiation is more appreciable especially for the western orientations which is higher [18] [21].

\subsection{Polar Diagram}

Indeed, analysis of Figure 6 indicates polar diagram of prevailing winds base on the cumulative energy. In this figure, each concentric radius is proportional to the intensity of the cumulative energy in the given direction.

In this figure, the cumulative energy diagram shows that, in this period of the $15^{\text {th }}$ of April 2018, the privilege directions were the North and South because they had the smallest cumulated energy; then come the semi-cardinal directions and finally the East and West one. Based on the different results obtained, and in the climatic context of Burkina Faso, building should be oriented Nord faces. 


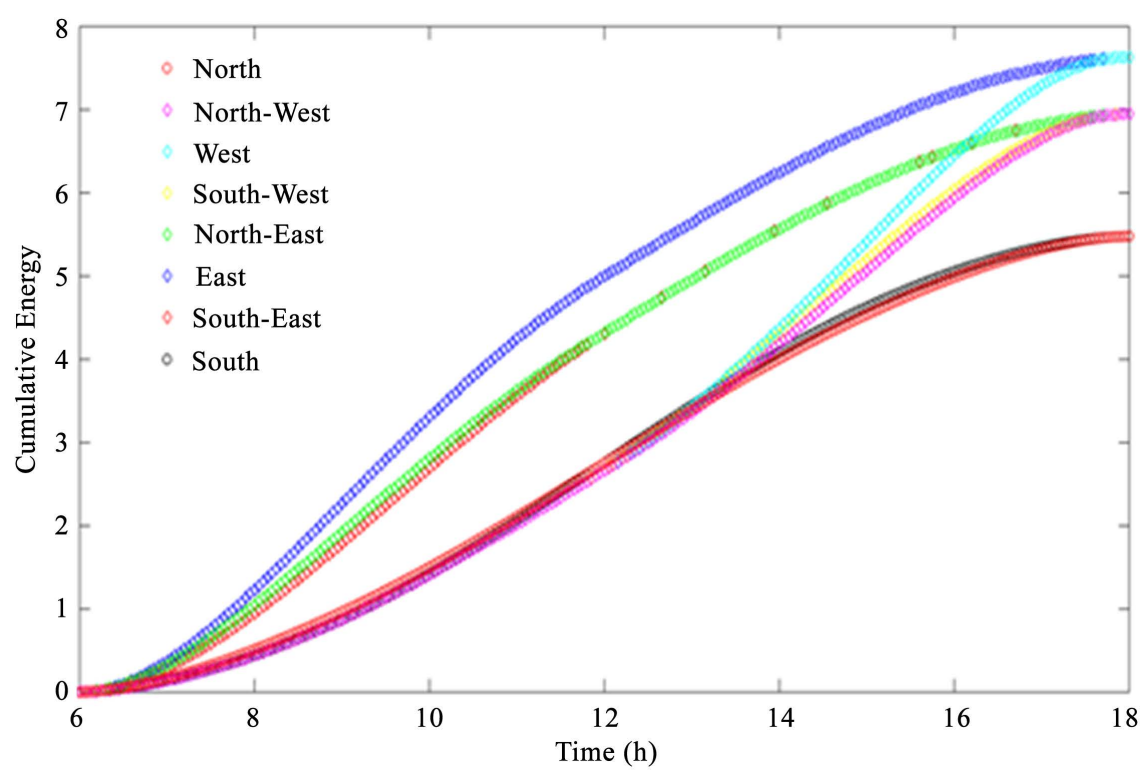

Figure 5. The cumulative energy received by different faces of the building with MATLAB.

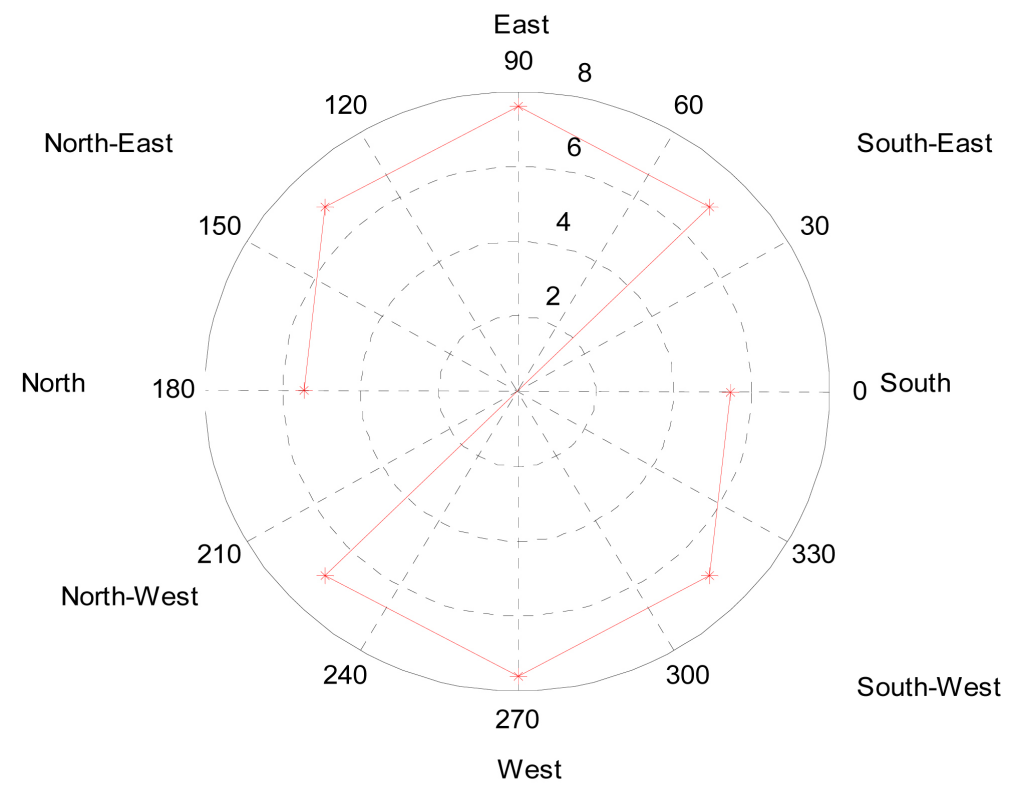

Figure 6. Diagram of cumulative energy of the $15^{\text {th }}$ April 2019.

The elongated East-west parallelepiped shape was found to reduce the effect of solar radiation, because small surfaces are exposed to maximum flow (the East facade before noon, and the West in the afternoon). In addition, this shape offers more natural ventilation.

\subsection{Impact of the Orientation on the Internal Temperature and the Relative Humidity}

The results from COMSOL 5.3a software simulations are presented in Figure 7 below and show the impact of the orientation of the exterior wall on the internal 


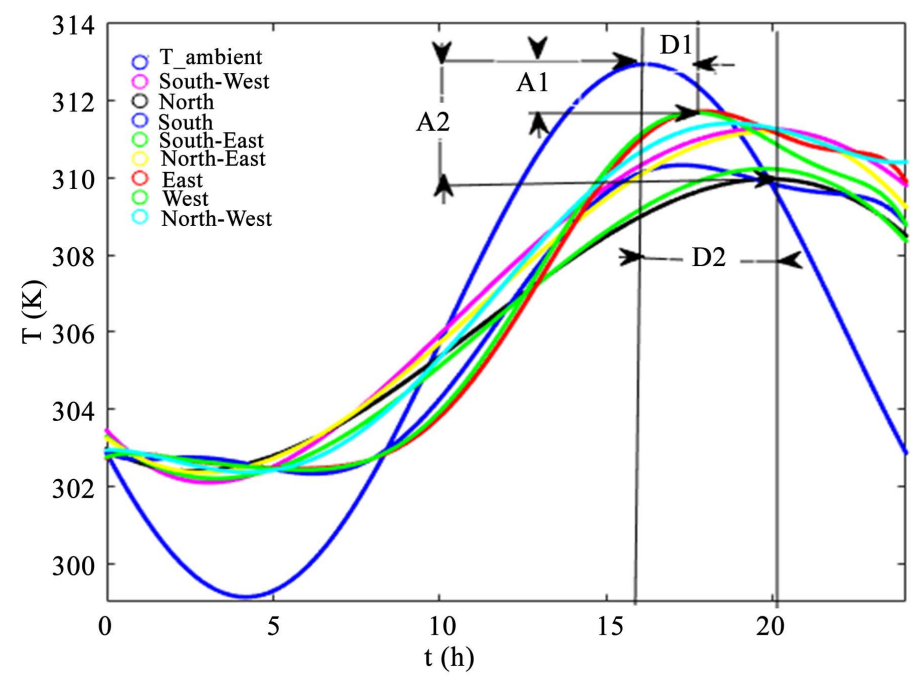

Figure 7. Impact of the orientation on the internal temperature of the building. $A_{1}$ : Thermal amplitude damping (east, west compare to ambient); $\mathrm{A}_{2}$ : Thermal amplitude damping (north, south compare to ambient); $\mathrm{D}_{1}$ : Thermal phase shift (east, west compare to ambient); $\mathrm{D}_{2}$ : Thermal phase shift (north, south compare to ambient).

behavior during the hottest period, in this case, the month of April is considered to be the hottest month in Burkina Faso. The orientations are noted with respect to the main facade. For example, if we say that a room faces northeast, it means that the main facade faces northeast. We then deduce the positions of the other walls. We also find that the average internal temperature from any orientation is everywhere the same early in the morning before 6 a.m. This can be explained by the fact that there is no solar radiation before sunrise.

From this Figure 7, we notice that consumption for air conditioning between West and East orientations is high compared to others orientations.

This is shows in the studies made by Berghout et al. [18] [19], and their findings showed that consumption was higher for West orientation than East orientation. We also note that, there is a thermal amplitude damping greater than $4^{\circ} \mathrm{C}$ between the North orientation and the ambient maximal temperature $\left(A_{2}\right)$, and we find practically the same thermal amplitude damping difference between the South and the maximum ambient temperature. This result is also obtain in [22] [23] in their study based on the orientation. The others orientations lead to a temperature difference less than $3^{\circ} \mathrm{C}\left(\mathrm{A}_{1}\right)$. The thermal phase shift between $\left(\mathrm{A}_{1}\right)$ the East or West orientation and the environment leads to two (2) hours, however, for the South and North and ambient orientation, there is a phase shift $\left(D_{2}\right)$ of about four and half ( $4 \mathrm{~h} 30 \mathrm{mn}$ ) hours.

In general, we notice on Figure 8, that, the relative hygrometry (humidity) within the cell does not vary too much versus orientation. We note, however, that it evolves in the opposite direction of the temperature. In the morning, we observe low temperature leading high values for hygrometry. Thermal comfort assessment, is different, depending on the society and for the same society, according to the individuals. For Sahelian zone, (tropical dry and hot), one 


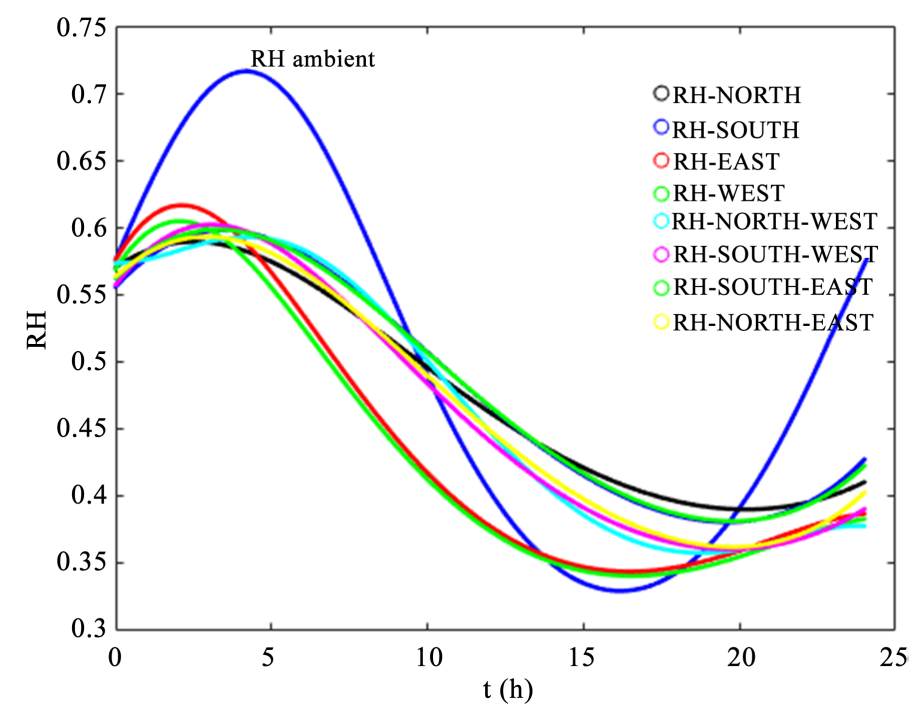

Figure 8. Relative hygrometry evolution with orientations.

considers that an ambiance describes by $(20 \leq T \leq 33)$ and $(30 \leq R H \leq 70)$ are tolerable hygro-thermal conditions. Those conditions are only met at the start of the day until 10 a.m.

\section{Conclusion}

The increasing trend in energy consumption of buildings will continue over during the coming years due to the expansion of built-up area and associated energy needs. In the hot arid zone climate like the city of Ouagadougou, it was found that orientation has a major impact on the amount of energy consumed by a building to achieve comfort for its users. Since energy conservation is one of the important considerations throughout the world and insolation of component of the envelope is an important strategy, we study the influence of thermal comfort based on the orientation of the walls. As the building is adapted to the local climate, it can benefit from the surrounding environment and achieve user's comfort. Therefore, the optimal design of building walls should help improve the thermal comfort especially since there are no standards relating to the thermal regulation of building materials in these countries. The simulation's result from COMSOL and MATLAB software showed that improvement of the thermal performance and comfort of a building could be possible trough orientation. It was found that a northern facade results in bringing the less energy consumption because of lower heating loads that arrives on it. However, the western facade causes the highest annual energy consumption by around $22 \%$ over than the northern façade. Based on all the simulations that were carried out, the worst orientations were "West and East": both of which recorded maximum average internal temperatures $\left(39^{\circ} \mathrm{C}\right)$ compared to the North-South axis orientation $\left(35^{\circ} \mathrm{C}\right)$ i.e., at least four $(4)$ Celsius degrees. On the other hand, the relative hygrometry varies in both cases between 0.62 and 0.33 ; this relative humidity interval is included in the thermal comfort zone with ventilation $(0.1 \mathrm{~m} / \mathrm{s})$. This 
observation shows that thermal comfort is much more dependent on temperature. This study can help in choosing the optimal orientations of a building and reducing at the same time the energy needs in a given building.

\section{Acknowledgements}

The ISP, Uppsala University, Sweden is gratefully acknowledged for their support to the project BUF01.

\section{Conflicts of Interest}

The authors declare no conflicts of interest regarding the publication of this paper.

\section{References}

[1] Cordier, N. (2007) Developpement et evaluation de strategies de controle de ventilation appliquees aux locaux de grandes dimensions. Thèse de Doctorat, Ecole Nationale des Travaux Publics de l'Etat, Lyon.

[2] Höppe, P. (2002) Different Aspects of Assessing Indoor and Outdoor Thermal Comfort. Energy Build, 34, 661-665. https://doi.org/10.1016/S0378-7788(02)00017-8

[3] Fati, A.O., Abdou Latif, B., Souleymane, O., Ky, S.M.T., Lewamy, M. and Joseph, B.D. (2020) The Impact of Local Materials on the Improvement of the Thermal Comfort in Building. Current Journal of Applied Science and Technology, 39, 22-35. https://doi.org/10.9734/cjast/2020/v39i1530713

[4] Zhang, W., Liu, F. and Fan, R. (2018) Improved Thermal Comfort Modeling for Smart Buildings: A Data Analytics Study. International Journal of Electrical Power \& Energy Systems, 103, 634-643. https://doi.org/10.1016/j.ijepes.2018.06.026

[5] Mosqueron, L. and Nedellec, V. (2001) Inventaire des données françaises sur la qualité de l'air à l'intérieur des bâtiments. Rue du Gén. Observatoire De La Qualité De L'Air Intérieur, Paris.

[6] Hema, C., Messan, A., Lawane, A., Soro, D., Nshimiyimana, P. and Van Moeseke, G. (2021) Improving the Thermal Comfort in Hot Region through the Design of Walls Made of Compressed Earth Blocks: An Experimental Investigation. Journal of Building Engineering, 38, Article ID: 102148. https://doi.org/10.1016/j.jobe.2021.102148

[7] Yu, J., Yang, C., Tian, L. and Liao, D. (2009) Evaluation on Energy and Thermal Performance for Residential Envelopes in Hot Summer and Cold Winter Zone of China. Applied Energy, 86, 1970-1985. https://doi.org/10.1016/j.apenergy.2009.01.012

[8] Pérez-Lombard, L., Ortiz, J. and Pout, C. (2008) A Review on Buildings Energy Consumption Information. Energy and Buildings, 40, 394-398. https://doi.org/10.1016/j.enbuild.2007.03.007

[9] Omrani, S., Garcia-Hansen, V., Capra, B. and Drogemuller, R. (2017) Natural Ventilation in Multi-Storey Buildings: Design Process and Review of Evaluation Tools. Building and Environment, 116, 182-194. https://doi.org/10.1016/j.buildenv.2017.02.012

[10] Abuseif, M. and Gou, Z. (2018) A Review of Roofing Methods: Construction Features, Heat Reduction, Payback Period and Climatic Responsiveness. Energies, 11, Article No. 3196. https://doi.org/10.3390/en11113196 
[11] Bonkaney, A., Madougou, S. and Adamou, R. (2017) Impacts of Cloud Cover and Dust on the Performance of Photovoltaic Module in Niamey. Journal of Renewable Energy, 2017, Article ID: 9107502. https://doi.org/10.1155/2017/9107502

[12] Ashmawy, R.E. and Azmy, N.Y. (2018) Buildings Orientation and its Impact on the Energy Consumption. Academic Research Community Publication, 2, 35-49. https://doi.org/10.21625/archive.v2i3.344

[13] Fati, A.O., Souleymane, O., Adrien, S., Amadou, K., Adama, O., Salifou, O., et al. (2021) Influences of Local Materials on the Building Behavior and Evaluation of the Cooling Loads. Journal de Physique de la SOAPHYS, 2, C20A19-1-C20A19-7. https://doi.org/10.46411/jpsoaphys.2020.02.19

[14] Hameed, P., Bin, N., Nor, M., Nallagownden, P., Elamvazuthi, I. and Ibrahim, T. (2016) Intelligent Multi-Objective Control and Management for Smart Energy Efficient Buildings. International Journal of Electrical Power \& Energy Systems, 74, 403-409. https://doi.org/10.1016/j.ijepes.2015.08.006

[15] Amadou Oumarou, F., Ramchandra, B., Mamadou, L., Ky, S.M.T., Ouedraogo, S., Rabani, A., Compaoré, A. and Bathiebo, D.J. (2020) Determination and Evaluation of the Cooling Load of a Building Made by Different Local Material of Construction. IRA-International Journal of Applied Sciences, 15, 1-14.

https://doi.org/10.21013/jas.v15.n5.p1

[16] Mirrahimi, S., Mohamed, M.F., Haw, L.C., Ibrahim, N.L.N., Yusoff, W.F.M. and Aflaki, A. (2016) The Effect of Building Envelope on the Thermal Comfort and Energy Saving for High-Rise Buildings in Hot-Humid Climate. Renewable and Sustainable Energy Reviews, 53, 1508-1519. https://doi.org/10.1016/j.rser.2015.09.055

[17] Fanger (1977) Thermal Analysis-HumaN Comfort-Indoor Environment. NBS Special Publication 491. NBS, Lyngby, 3-17.

[18] Berghout, B., Forgues, D. and Monfet, D. (2014) Simulation du confort thermique intérieur pour l'orientation d'un bâtiment collectif à Biskra, Algérie. eSIM 2014 Conference Proceedings, Ottawa, 8-9 May 2014, 14.

[19] Fernandez, P. and Lavigne, P. (2009) Concevoir des batiments bioclimatiques: Fondements et méthodes. Ed.le Moni, Paris.

[20] Samira, L. and Abdou, S. (2010) Impact de l'orientation sur le confort thermique interieur dans l'habitation collective. Sciences \& Technologie D, No. 32, 33-40.

[21] Bellara Louafi, S. and Abdou, S. (2009) Impact de l'orientation sur le confort thermique interieur dans l'habitation collective: Cas de la nouvelle ville Ali Mendjeli de Constantine. Sciences \& Technologie A, No. 29, 61-68.

[22] Guermia, B. and Fatiha, B. (2010) L'impact de l'orientation des parois transparentes sur le confort thermique dans une salle de classe a constantine. Sciences \& technologie $D$, No. 31, 71-80.

[23] Al-Obaidi, M.A.A.H. and Woods, P. (2006) Investigations on Effect of the Orientation on Thermal Comfort in Terraced Housing in Malaysia. International Journal of Low-Carbon Technologies, 1, 167-176. https://doi.org/10.1093/ijlct/1.2.167

[24] Kottek, M., Grieser, J., Beck, C., Rudolf, B. and Rubel, F. (2006) World Map of the Köppen-Geiger Climate Classification Updated. Meteorologische Zeitschrift, 15, 259-263. https://doi.org/10.1127/0941-2948/2006/0130

[25] Kaboré, M. (2015) Enjeux de la simulation pour l'étude des performances énergétiques des bâtiments en Afrique sub-saharienne. Université Grenoble Alpes.

[26] Chang, J.H. (2016) Thermal Comfort and Climatic Design in the Tropics: An His- 
torical Critique. The Journal of Architecture, 21, 1171-1202. https://doi.org/10.1080/13602365.2016.1255907

[27] Kabore, B., Kam, S.I.E., Wende, G., Ouedraogo, P. and Bathiebo, D.J. (2018) Etude de l'évolution climatique au Burkina Faso de 1983 à 2012: Cas des villes de Bobo Dioulasso, Ouagadougou et Dori. Arabian Journal of Geosciences, 4, 50-59.

[28] Gerlich, V. (2011) Modelling of Heat Transfer in Buildings. 25th European Conference on Modelling and Simulation, ECMS 2011, Krakow, 7-10 June 2011, 244-248. https://doi.org/10.7148/2011-0244-0248

[29] Compaoré, A. (2018) Etude des performances thermiques d'un habitat type du Burkina Faso. Application: Contribution à la mise en place d'une règlementation thermique. Université Ouaga I Professeur JOSEPH KI-ZERBO, Ouagadougou.

[30] Compaore, A., Ouedraogo, B., Guengane, H., Malbila, E. and Bathiebo, D.J. (2017) Role of Local Building Materials on the Energy Behaviour of Habitats in Ouagadougou. IRA-International Journal of Applied Sciences, 8, 63-72. https://doi.org/10.21013/jas.v8.n2.p3

[31] Charvátová, H., Procházka, A. and Zálešák, M. (2018) Computer Simulation of Temperature Distribution during Cooling of the Thermally Insulated Room. Energies, 11, Article No. 3025. https://doi.org/10.3390/en11113205 